\title{
Knowledge and determinants regarding tuberculosis among medical students in Hunan, China: a cross-sectional study
}

Yangjiang $\mathrm{Ou}^{1 \dagger}{ }^{1 \dagger}$ Zhenzhou $\mathrm{Luo}^{2 \dagger}$, Jinsong Mou${ }^{3 *}$ (D) Hui Ming ${ }^{4}$, Xiang Wang ${ }^{5}$, Shipeng Yan $^{6}$ and Aichun $\operatorname{Tan}^{7}$

\begin{abstract}
Background: Tuberculosis (TB) is one of the most common infectious diseases worldwide. Insufficient TB knowledge may increase the risk of contracting the disease among medical students. The purpose of this study was to assess the level of TB knowledge and analyse related determinants among medical students.

Methods: A cross-sectional study was performed among final-year medical students from three main undergraduate medical universities in Hunan Province. TB knowledge, attitude and practice were assessed using a questionnaire. A t-test and multiple linear regression analysis were conducted to explore the association between TB knowledge and influencing factors.

Results: The total mean percentage of correct answers for TB knowledge was 44.4\% (SD 13.5\%), including 52.5\% (SD 16.8\%) for epidemiology and prevention, 35.7\% (SD 16.1\%) for diagnosis, and 47.5\% (SD 22.7\%) for treatment. Medical students who reported observing at least one TB case and an X-ray of a TB patient had a higher percentage of correct answers for epidemiology and prevention ( $54.4 \%$ vs $43.9 \%, p<0.001 ; 54.3 \%$ vs $42.1 \%, p<0.001$ ), diagnosis (37.2\% vs $29.0 \%, p<0.001 ; 37.1 \%$ vs $27.5 \%, p<0.001)$, treatment $(50.0 \%$ vs $36.0 \%, p<0.001 ; 49.5 \%$ vs $35.7 \%, p<0.001)$ and total score $(46.2 \%$ vs $36.2, p<0.001 ; 46.0 \%$ vs $34.7 \%, p<0.001)$. Older medical students ( $\geq 23$ years) had greater knowledge than younger medical students ( $<23$ years) regarding diagnosis (37.2\% vs $31.7 \%, p<0.001)$. The multivariable linear regression analysis determined an association between observing at least one TB case and an $X$-ray of a TB patient and greater knowledge of epidemiology and prevention ( $\beta=5.6,95 \% \mathrm{Cl}$ : $2.3,8.9 ; \beta=8.2,95 \% \mathrm{Cl}: 4.6,11.8)$, diagnosis $(\beta=3.9,95 \% \mathrm{Cl}: 0.8,7.1 ; \beta=5.7,95 \% \mathrm{Cl}: 2.2,9.2)$ and treatment $(\beta=10.1$, $95 \% \mathrm{Cl}: 5.6,14.5 ; \beta=7.0,95 \% \mathrm{Cl}: 2.2,11.8)$ and a higher total score $(\beta=5.5,95 \% \mathrm{Cl}: 2.9,8.1 ; \beta=6.6,95 \% \mathrm{Cl}: 3.8,9.5)$. Moreover, an older age ( $\geq 23$ years) was associated with more accurate knowledge of diagnosis ( $\beta=3.9,95 \% \mathrm{Cl}: 1.8,6.1)$ and a higher total score $(\beta=2.8,95 \% \mathrm{Cl}: 1.1,4.6)$.
\end{abstract}

Conclusion: Poor TB knowledge was observed among medical students, which implied a need to innovate our current infectious disease curriculum to promote TB knowledge and practices among medical students.

Keywords: Knowledge, Determinants, Tuberculosis, Medical students

\footnotetext{
* Correspondence: jinsong.mou@gmail.com

†Yangjiang Ou and Zhenzhou Luo contributed equally to this work.

Yangjiang $\mathrm{Ou}$ and Zhenzhou Luo are co-first authors.

${ }^{3}$ Shenzhen Pingshan Maternal and Child Health Hospital, Shenzhen 518122,

People's Republic of China

Full list of author information is available at the end of the article
}

(c) The Author(s). 2018 Open Access This article is distributed under the terms of the Creative Commons Attribution 4.0 International License (http://creativecommons.org/licenses/by/4.0/), which permits unrestricted use, distribution, and reproduction in any medium, provided you give appropriate credit to the original author(s) and the source, provide a link to the Creative Commons license, and indicate if changes were made. The Creative Commons Public Domain Dedication waiver (http://creativecommons.org/publicdomain/zero/1.0/) applies to the data made available in this article, unless otherwise stated. 


\section{Background}

Tuberculosis (TB) is one of the most common infectious diseases worldwide and continues to be a major public health problem for low and middle-income countries. Several effective strategies have been implemented by the World Health Organization (WHO) to prevent and control the disease, including the directly observed treatment, short-course (DOTS) and stop TB strategies $[1,2]$. The Millennium Development Goals (MDGs) [3], which were developed to halt and reverse the TB incidence by 2015, have been achieved, with a total reduction of $18 \%$ worldwide, and the death rate is half that reported in 1990 [4]. Despite these gains, the epidemic remains serious. The Global TB Report 2017 [5] published by the WHO reported that, although the fight against TB was paying off, 1.674 million people died from TB in 2016, and the disease ranked as the leading cause of death from a single infectious agent above HIV/ AIDS. The report also showed that China, India and Indonesia alone accounted for $45 \%$ of global cases in 2016 and that China had a high TB burden even though the country had achieved the MDGs to reduce the prevalence of smear-positive TB by 50\% in 2010 [6].

TB trends are influenced by control programmes as well as by biological, social and economic factors [7]. Undoubtedly, a lack of knowledge regarding TB among health care workers may contribute to an increased risk of developing the disease [8,9]. A study of Chinese TB patients showed that a TB diagnostic delay was related to health facility staff factors, including inadequate TB knowledge, inability to prescribe a smear test for suspected TB cases, inability to refer suspected TB cases to county TB dispensaries or designated hospitals for TB care and misdiagnosis [10]. In this context, TB knowledge among medical students is particularly important; thus, undergraduate training regarding $\mathrm{TB}$ should be strengthened, because students may face significant exposures and consequently have the highest risk of infection or disease [11]. Furthermore, because medical students are potential future physicians and leaders, these students need to understand the epidemiology, determinants, screening and management of TB to promote effective prevention, early diagnosis, and successful treatment [12].

However, several studies [13-15] have reported that the TB knowledge of undergraduate medical students is insufficient. Medical colleges play an important role in training and shaping the attitudes of the future generations of medical practitioners [14]. Although TB health education in schools was emphasized at all times in China, researchers [16, 17] found that TB knowledge and practices among medical students were generally inadequate. A dearth of data regarding TB knowledge exists among medical students in China. Moreover, Hunan
Province reported a notifiable TB incidence rate of 83.0 per 100,000 populations, which was the fourth highest incidence in China [18]. With this background, this study was conducted to survey 1088 preclinical undergraduate students from three medical universities in Hunan Province with the objective of assessing TB knowledge among final-year medical students and analysing the related determinants. Our findings can serve as baseline information for TB knowledge and help improve future TB prevention and control strategies in the region.

\section{Methods}

\section{Study population}

A cross-sectional study was conducted among three main undergraduate medical universities located in Changsha, which is the capital of Hunan Province, China, from March to June of 2016. Final-year medical students were recruited, because they had taken the infectious disease course prior to this investigation.

\section{The questionnaire}

The questionnaire was designed based on the report of Laurenti [19] and adjusted appropriately. The questionnaire focused on two dimensions: attitudes and experiences and knowledge of epidemiology and prevention, diagnosis and treatment. Each question had five possible answers, of which only one was correct. The students were asked to circle the most appropriate answer independently without receiving any help completing the questionnaire. All students participated on a voluntary basis and were not remunerated for their contribution.

\section{Data analysis}

The information was recorded in a database using EpiData 3.0 and analysed using SPSS 18.0. The data are reported as percentages. The total score for all questions and separate scores for epidemiology and prevention, diagnosis, and treatment were calculated. In addition, the mean percentage scores in different subpopulations were calculated based on demographic variables, experiences, and attitudes. Descriptive statistics and t-tests were used to analyse differences in different subpopulations. A multivariable linear regression analysis was performed to analyse the determinants associated with epidemiology and prevention, diagnosis, and treatment on TB knowledge.

\section{Results}

\section{General characteristics of the participants}

A total of 1200 undergraduate medical university students were surveyed, of whom 112 were excluded due to incomplete responses or logical errors. A total of 1088 valid questionnaires were received, for a response rate of $90.7 \%$. Table 1 shows the characteristics of the participants. A 
Table 1 Demographic characteristics, experiences and attitudes of participants

\begin{tabular}{lll}
\hline Characteristics of participants & Number & Percent \\
\hline Demographic & & \\
Gender & & \\
$\quad$ Male & 435 & 40.0 \\
$\quad$ Female & 653 & 60.0 \\
Age (Std. Dev.) & $23(0.92)$ & \\
Experiences and Attitudes & & \\
Received PPD test & 160 & 14.7 \\
$\quad$ Yes & 928 & 85.3 \\
$\quad$ No & & 7.1 \\
Performed at least one PPD test & 77 & 92.9 \\
$\quad$ Yes & 1011 & \\
$\quad$ No & & 81.9 \\
Observed at least one TB case & 891 & 18.1 \\
$\quad$ Yes & 197 & \\
$\quad$ No & & \\
Observed at least one X-ray of TB case & & 14.6 \\
Yes & 929 & \\
No & 159 & \\
Y'm at risk for TB & & \\
No & 795 & \\
\hline
\end{tabular}

total of $435(40.0 \%)$ and $653(60.0 \%)$ of the respondents were male and female, respectively, resulting in a gender ratio of 1:1.5. The mean age was $23 \pm 0.92$ years, and the ages ranged between 20 and 25 years. Only 160 (14.7\%) of the students had received a PPD (purified protein derivative) test, and only 77 (10\%) had performed at least one PPD test. More than $80 \%$ of the students had observed at least one case of TB and an X-ray of a TB patient $(n=891$, $81.9 \%$ and $n=929,85.4 \%$, respectively). Approximately one-fourth $(n=293,26.9 \%)$ of the students were aware of being at risk for TB infection.

\section{Knowledge about the epidemiology and prevention, diagnosis, and treatment of TB}

The total mean percentage of correct answers for $\mathrm{TB}$ knowledge was $44.4 \%$ (SD $13.5 \%$ ). The mean percentages of correct answers were $52.5 \%$ (SD 16.8\%) for epidemiology and prevention, 35.7\% (SD 16.1\%) for diagnosis, and $47.5 \%$ (SD 22.7\%) for treatment. In the epidemiology and prevention dimension (Table 2), the mean score for "BCG (bacille Calmette-Guerin) is a vaccine for TB" was relatively high at $90.6 \%$, whereas the mean score for "The Mycobacterium avium complex is the most frequent aetiologic agent of TB" was lowest at $6.4 \%$.
Table 2 Mean percentage of correct answers in epidemiology and prevention

\begin{tabular}{|c|c|}
\hline Correct answers & $\begin{array}{l}\text { Mean } \\
\text { percentage (\%) }\end{array}$ \\
\hline$B C G$ is a vaccine for $T B$ & 90.6 \\
\hline TB transmitted via airborne & 89.7 \\
\hline $\begin{array}{l}\text { Higher incidence and delay in diagnosis of TB } \\
\text { related to disequalities, Socio-economic issues } \\
\text { and low resources of native country }\end{array}$ & 67.7 \\
\hline Prevalence of TB in India and China is highest & 64.9 \\
\hline $\begin{array}{l}\text { Health operators, immigrants, elderly, children, } \\
\text { immunosuppressed patients are at more risk of TB }\end{array}$ & 63.5 \\
\hline $\begin{array}{l}\text { Masks are necessary for entering a room } \\
\text { where an open TB patient stays }\end{array}$ & 55.9 \\
\hline The current TB vaccine is live attenuated vaccine & 52.2 \\
\hline $\begin{array}{l}\text { Patients with both latent TB infection } \\
\text { and HIV infection will increase the risk for } \\
\text { developing active TB }\end{array}$ & 44.8 \\
\hline $\begin{array}{l}\text { TB vaccination in low prevalence populations } \\
\text { is not useful in controlling the spread of TB }\end{array}$ & 41.2 \\
\hline $\begin{array}{l}\text { Isolate an open pulmonary TB patient using } \\
\text { a negative pressure room }\end{array}$ & 38.7 \\
\hline HIV is strongly related with the TB bacillus & 37.7 \\
\hline $\begin{array}{l}\text { The prevalence of TB in China is currently } \\
60-70 \text { cases per 100,000 people }\end{array}$ & 28.9 \\
\hline $\begin{array}{l}\text { Mycobacterium Avium Complex is the most } \\
\text { frequent aetiologic agent of TB }\end{array}$ & 6.4 \\
\hline
\end{tabular}

In the diagnosis dimension (Table 3), the mean score for "A sputum test is necessary to detect suspected pulmonary TB" was highest at $69.9 \%$, whereas the mean score for "Koch bacillus identification is always performed using a Ziehl-Neelsen stain" was lowest at 8.8\%.

In the treatment dimension (Table 3), the mean score for "Penicillin G is not useful for TB treatment" was highest at $74.6 \%$, whereas the mean score for "TB patients are supposed to be hospitalized for effective treatment every 7-10 days" was lowest at $19.2 \%$.

\section{Determinants of TB knowledge}

Table 4 shows the lack of an association between gender and the mean percentage of correct answers. The older medical students ( $\geq 23$ years) had more knowledge than the younger medical students ( $<23$ years) regarding epidemiology and prevention $(53.6 \%$ vs $49.6 \%, p=0.001)$, diagnosis $(37.2 \%$ vs $31.7 \%, p<0.001)$ and treatment $(49.0 \%$ vs $43.5 \%, p<0.001)$ and higher total scores $(45.7 \%$ vs $40.8 \%, p<0.001)$. Medical students who reported receiving a PPD test had a higher percentage of correct answers in the total score (46.3\% vs $44.0 \%, p=0.047$ ); conversely, no association was found between whether medical students reported performing at least one PPD test and the mean percentage of correct answers. Medical students 
Table 3 Mean percentage of correct answers in diagnosis and treatment

\begin{tabular}{|c|c|}
\hline Correct answers & $\begin{array}{l}\text { Mean } \\
\text { percentage (\%) }\end{array}$ \\
\hline \multicolumn{2}{|l|}{ Diagnosis } \\
\hline $\begin{array}{l}\text { Sputum test is necessary to detect } \\
\text { suspected pulmonary TB }\end{array}$ & 69.9 \\
\hline $\begin{array}{l}\text { Chest } x \text {-ray is recommended when someone } \\
\text { has a positive tuberculin skin test }\end{array}$ & 63.4 \\
\hline $\begin{array}{l}\text { Lung, brain, kidney could be } \\
\text { affected by M. Tuberculosis }\end{array}$ & 53.7 \\
\hline $\begin{array}{l}\text { Positive intradermal reaction test indicates } \\
\text { increased sensitization to drugs }\end{array}$ & 50.2 \\
\hline $\begin{array}{l}\text { First contact with bacteria causes } \\
\text { a primary complex }\end{array}$ & 47.9 \\
\hline $\begin{array}{l}\text { Patients and health operators which } \\
\text { come in contact with a TB patient } \\
\text { should receive PPD test }\end{array}$ & 37.4 \\
\hline $\begin{array}{l}\text { PPD test is positive from an induration } \\
\text { diameter of } 5 \mathrm{~mm}\end{array}$ & 36.9 \\
\hline PPD test is an intradermal injection & 31.3 \\
\hline The immune response to TB is cell mediated & 27.4 \\
\hline $\begin{array}{l}\text { "Quantiferon TB gold" test can differentiate } \\
\text { infection from other reasons for testing positive }\end{array}$ & 22.7 \\
\hline $\begin{array}{l}\text { It is an expression of immune response to } \\
\text { mycobacterial antigens which is not a limit } \\
\text { of tuberculin skin test. }\end{array}$ & 20.6 \\
\hline $\begin{array}{l}\text { After } 5 \text { weeks, the primary infection does } \\
\text { tuberculin test result will become positive }\end{array}$ & 19.5 \\
\hline Tine test is a multiple puncture test & 10.1 \\
\hline $\begin{array}{l}\text { Koch bacillus identification is always } \\
\text { performed through Ziehl-Neelsen stain }\end{array}$ & 8.8 \\
\hline \multicolumn{2}{|l|}{ Treatment } \\
\hline Penicillin $\mathrm{G}$ is not useful for TB treatment & 74.9 \\
\hline $\begin{array}{l}\text { In case of positive PPD test in an exposed } \\
\text { health operator, he/she should be assessed } \\
\text { for further investigations and for prophylactic } \\
\text { treatment with isoniazid }\end{array}$ & 61.3 \\
\hline $\begin{array}{l}\text { Prophylactic treatment with isoniazid is } \\
\text { implemented to close contacts resulted } \\
\text { negative to the test }\end{array}$ & 46.6 \\
\hline $\begin{array}{l}\text { Consider an active TB woman in homecare } \\
\text { therapy who has recently discovered to be } \\
\text { pregnant, she should be informed that } \\
\text { tuberculosis does not increase the risk of } \\
\text { miscarriage and treatment should be } \\
\text { changed because there is a potential risk of } \\
\text { toxicity for the child }\end{array}$ & 35.7 \\
\hline $\begin{array}{l}\text { TB patient supposed to be hospitalized for an } \\
\text { effective treatment every } 7-10 \text { days }\end{array}$ & 19.2 \\
\hline
\end{tabular}

who reported observing at least one $\mathrm{TB}$ case and one $\mathrm{X}$-ray for a TB case had higher percentages of correct answers for epidemiology and prevention (54.4\% vs $43.9 \%, p$ $<0.001 ; 54.3 \%$ vs $42.1 \%, p<0.001)$, diagnosis $(37.2 \%$ vs $29.0 \%, p<0.001 ; 37.1 \%$ vs $27.5 \%, p<0.001)$, and treatment (50.0\% vs $36.0 \%, p<0.001 ; 49.5 \%$ vs $35.7 \%, p<0.001)$ and higher total scores $(46.2 \%$ vs $36.2 \%, p<0.001 ; 46.0 \%$ vs $34.7 \%, p<0.001)$. Medical students who were aware of themselves being at risk for TB reported a similar percentage of correct answers with the other students.

The multivariable linear regression analysis (Table 5) identified an association between observing at least one TB case and an X-ray of a TB case and greater knowledge regarding epidemiology and prevention $(\beta=5.6$, 95\% CI: 2.4, 8.9; $\beta=8.2,95 \%$ CI: 4.6, 11.8), diagnosis $(\beta=3.9,95 \%$ CI: $0.8,7.1 ; \beta=5.7,95 \%$ CI: $2.2,9.2)$, treatment $(\beta=10.1,95 \% \mathrm{CI}: 5.6,14.5 ; \beta=7.0,95 \% \mathrm{CI}$ : $2.2,11.8)$ and total scores $(\beta=5.5,95 \%$ CI: $2.9,8.1 ; \beta$ $=6.6,95 \%$ CI: 3.8, 9.5). Moreover, older medical students ( $\geq 23$ years) had more accurate knowledge regarding diagnosis $(\beta=3.9,95 \%$ CI: $1.8,6.1)$ and higher total scores $(\beta=2.8,95 \% \mathrm{CI}: 1.1,4.6)$. In addition, medical students who considered themselves not at risk for TB were associated with greater knowledge about treatment $(\beta=-3.5,95 \% \mathrm{CI}$ : $-6.5,-0.6)$.

\section{Discussion}

We found that medical students had generally poor knowledge about TB. More than $50 \%$ of the total questions regarding TB knowledge were incorrect, which was consistent with another survey conducted in southwest China in 2011 [16] that reported that fewer than half the students had knowledge of TB symptoms of cough/ blood-tinged sputum, local TB dispensaries and the national free TB treatment policy. Compared with the results reported by Laurenti [19], the total mean percentage of correct answers in our study was lower ( $44.4 \%$ vs $56.5 \%$ ), as were those for epidemiology and prevention $(52.5 \%$ vs $63.5 \%)$ and diagnosis $(35.7 \%$ vs $54.1 \%)$; however, our results regarding treatment were slightly higher $(47.5 \%$ vs $45.7 \%)$. Moreover, the general knowledge level for TB in the present study was inferior to other surveys conducted among medical students in Italy [11], Brazil [13], and National TB Curriculum Consortium (NTCC) schools [20], which suggested a considerable need for improvement in TB knowledge among medical students. Because this lack of knowledge may be an influencing factor for a higher TB prevalence, improved instruction in TB for medical students is necessary.

Medical students' attitudes towards TB may play an integral role in how they manage TB patients during their careers [21]. However, our study indicated that the majority of medical students lacked an accurate TB attitude. Approximately one-quarter of the medical students considered themselves at risk of contracting TB, which was consistent with the results reported by Bhandari [22]. Nevertheless, in the subsequent multiple linear regression analysis, we observed a negative association between attitude and the level of knowledge of TB treatment. In other words, the medical 
Table 4 Mean percentage of correct answer by demographic characteristics, experiences and attitudes of participants

\begin{tabular}{|c|c|c|c|c|c|c|c|c|}
\hline & \multicolumn{2}{|c|}{ Epidemiology and prevention } & \multicolumn{2}{|l|}{ Diagnosis } & \multicolumn{2}{|l|}{ Treatment } & \multicolumn{2}{|l|}{ Total } \\
\hline & Mean score & $P$-value & Mean score & $P$-value & Mean score & $P$-value & Mean score & $P$-value \\
\hline \multicolumn{9}{|l|}{ Gender } \\
\hline Male & 51.8 & 0.316 & 35.8 & 0.801 & 48.9 & 0.092 & 44.4 & 0.947 \\
\hline Female & 52.9 & & 35.6 & & 46.6 & & 44.3 & \\
\hline \multicolumn{9}{|l|}{ Age } \\
\hline$<23$ & 49.6 & 0.001 & 31.7 & $<0.001$ & 43.5 & $<0.001$ & 40.8 & $<0.001$ \\
\hline$\geq 23$ & 53.6 & & 37.2 & & 49.0 & & 45.7 & \\
\hline \multicolumn{9}{|c|}{ Received PPD test } \\
\hline Yes & 54.2 & 0.153 & 38.0 & 0.070 & 47.5 & 0.990 & 46.3 & 0.047 \\
\hline No & 52.2 & & 35.3 & & 47.5 & & 44.0 & \\
\hline \multicolumn{9}{|c|}{ Performed at least one PPD test } \\
\hline Yes & 53.9 & 0.426 & 36.8 & 0.523 & 47.5 & 0.990 & 45.5 & 0.462 \\
\hline No & 52.4 & & 35.6 & & 47.5 & & 44.3 & \\
\hline \multicolumn{9}{|c|}{ Observed at least one TB case } \\
\hline Yes & 54.4 & $<0.001$ & 37.2 & $<0.001$ & 50.0 & $<0.001$ & 46.2 & $<0.001$ \\
\hline No & 43.9 & & 29.0 & & 36.0 & & 36.2 & \\
\hline \multicolumn{9}{|c|}{ Observed at least one X-ray of TB case } \\
\hline Yes & 54.3 & $<0.001$ & 37.1 & $<0.001$ & 49.5 & $<0.001$ & 46.0 & $<0.001$ \\
\hline No & 42.1 & & 27.5 & & 35.7 & & 34.7 & \\
\hline \multicolumn{9}{|c|}{ I'm at risk for TB } \\
\hline Yes & 53.2 & 0.395 & 35.1 & 0.429 & 45.5 & 0.072 & 44.0 & 0.651 \\
\hline No & 52.2 & & 35.9 & & 48.3 & & 44.5 & \\
\hline
\end{tabular}

students who believed they were not at risk of contracting TB had a higher level of knowledge of TB treatment. This finding disclosed that the medical students in our study lacked prevention awareness, although they had comparatively more TB knowledge. Therefore, we could infer that a relationship did not necessarily exist between knowledge and attitudes for $\mathrm{TB}$ and that higher levels of knowledge did not result in positive attitudes. However, this result might have been influenced by the sample size and questions asked. Admittedly, correct knowledge and positive perceptions towards TB were prerequisites to seek early prevention and control measures.

In our study, more than $80 \%$ of the medical students had observed at least one TB case and an X-ray of a TB patient; these students reflected a better grasp of $\mathrm{TB}$ knowledge. Furthermore, the multivariable linear regression analysis showed a significant association between observing at least one TB case and an X-ray of a TB patient and greater knowledge of epidemiology and prevention, diagnosis, and treatment and the total score. This finding suggested that clinical experience was important for promoting TB knowledge among medical students. This result might be related to the amount of curriculum time devoted to $\mathrm{TB}$ and the number of $\mathrm{TB}$ patients seen by the students [20, 23]. However, Hoffman [24] reported in 2016 that even among health professionals, a significant gap remained for improvement of knowledge and practices regarding TB.

We also found that older medical students ( $\geq 23$ years) had more accurate TB knowledge about the diagnosis and total scores, leading to a positive association between age and the level of TB knowledge. Similarly, a study by Montagna [11] reported that correct answers to questions concerning $\mathrm{TB}$ and its vaccine were associated with increasing age. TB knowledge increased with age, probably because older medical students developed more correct attitudes and behaviours regarding the disease. The TB course schedule might also be responsible for this finding.

To appropriately address the specialized problems of TB prevention and control, education and competence need to be strengthened among health care providers. The U.S. National Institutes of Health (NIH) funded the NTCC in 2003 to develop educational programmes to improve TB knowledge and practices among health professions students [20]. China also published the National Guideline for TB control, which emphasized TB health education [25]. Compared to traditional teaching, modern training methods, such as student-based teaching methods (problem-based learning), lead to improved 
Table 5 Multiple linear regression analysis of determinants of the percentage of correct answers

\begin{tabular}{|c|c|c|c|c|c|c|}
\hline & $\beta$ & $S_{b}$ & $b^{\prime}$ & t & $P$ & $95 \% \mathrm{Cl}$ \\
\hline \multicolumn{7}{|c|}{ Epidemiology and prevention } \\
\hline constant & 40.8 & 1.3 & & 30.6 & $<0.001$ & $(38.2,43.5)$ \\
\hline \multicolumn{7}{|c|}{ Observed at least one TB case } \\
\hline Yes & 5.6 & 1.7 & 0.1 & 3.4 & 0.001 & $(2.4,8.9)$ \\
\hline \multicolumn{7}{|c|}{ Observed at least one X-ray of TB case } \\
\hline Yes & 8.2 & 1.8 & 0.2 & 4.5 & $<0.001$ & $(4.6,11.8)$ \\
\hline \multicolumn{7}{|l|}{ Diagnosis } \\
\hline constant & 24.8 & 1.4 & & 17.8 & $<0.001$ & $(22.0,27.5)$ \\
\hline \multicolumn{7}{|l|}{ Age } \\
\hline$\geq 23$ & 3.9 & 1.1 & 0.1 & 3.6 & $<0.001$ & $(1.8,6.1)$ \\
\hline \multicolumn{7}{|c|}{ Observed at least one TB case } \\
\hline Yes & 3.9 & 1.6 & 0.1 & 2.4 & 0.015 & $(0.8,7.1)$ \\
\hline \multicolumn{7}{|c|}{ Observed at least one X-ray of TB case } \\
\hline Yes & 5.7 & 1.8 & 0.1 & 3.2 & 0.001 & $(2.2,9.2)$ \\
\hline \multicolumn{7}{|l|}{ Treatment } \\
\hline constant & 34.2 & 1.8 & & 18.7 & $<0.001$ & $(30.6,37.8)$ \\
\hline \multicolumn{7}{|c|}{ Observed at least one TB case } \\
\hline Yes & 10.1 & 2.3 & 0.2 & 4.5 & $<0.001$ & $(5.68,14.5)$ \\
\hline \multicolumn{7}{|c|}{ Observed at least one X-ray of TB case } \\
\hline Yes & 7.0 & 2.5 & 0.1 & 2.8 & 0.005 & $(2.2,11.8)$ \\
\hline \multicolumn{7}{|c|}{ I am at risk for TB } \\
\hline Yes & -3.5 & 1.5 & -0.1 & -2.4 & 0.019 & $(-6.5,-0.6)$ \\
\hline \multicolumn{7}{|l|}{ Total } \\
\hline constant & 32.1 & 1.1 & & 28.3 & $<0.001$ & $(29.9,34.4)$ \\
\hline \multicolumn{7}{|l|}{ Age } \\
\hline$\geq 23$ & 2.8 & 0.9 & 0.1 & 3.2 & 0.002 & $(1.1,4.6)$ \\
\hline \multicolumn{7}{|c|}{ Observed at least one TB case } \\
\hline Yes & 5.5 & 1.3 & 0.2 & 4.2 & $<0.001$ & $(2.9,8.1)$ \\
\hline \multicolumn{7}{|c|}{ Observed at least one $\mathrm{X}$-ray of TB case } \\
\hline Yes & 6.7 & 1.5 & 0.2 & 4.6 & $<0.001$ & $(3.8,9.5)$ \\
\hline
\end{tabular}

student satisfaction and provide additional learning opportunities [26]. Hence, the results of the present study highlight a demand to innovate modern educational methods to promote knowledge and social responsibility among medical students.

\section{Limitations}

Our study has several limitations. First, the questionnaire from Laurenti may not be comprehensive and appropriately adapted to the specific situation in China. Second, the representativeness of the sample needs to be improved further by increasing the sample size or adopting randomized sampling methods. Third, gauging a person's attitude towards TB based solely on the question "I am at risk for TB" is insufficient. This issue should be improved in a future study. Fourth, due to the cross-sectional study design, the causal relationship between the TB knowledge level and determinants could not be explored; however, the findings provide a basis for acquiring and testing a causal hypothesis. Finally, some reporting bias may have been inherent in this study design.

\section{Conclusion}

The present study found poor knowledge of TB among final-year medical students and considerable room for improvement in terms of TB knowledge, attitudes and practices. Moreover, practical clinical experience, attitude and age were significantly associated with more TB knowledge through a multiple linear regression analysis. We present the current status of TB knowledge levels among medical students and promote the need for active-learning methodologies. 


\section{Abbreviations}

BCG: Bacille Calmette-Guerin; Cl: Confidence interval; MDGs: Millennium Development Goals; PPD: Purified protein derivative; SD: Standard deviation; TB: Tuberculosis; WHO: World Health Organization

\section{Acknowledgements}

The authors thank the Hunan Institute for Tuberculosis Control \& Hunan Chest Hospital for kindly providing guidance and support and all of the students who filled in the questionnaire.

\section{Availability of data and materials}

The datasets generated and/or analysed during the current study are not publicly available due to data restrictions but are available from the corresponding author on reasonable request and pending approval by the school authorities.

\section{Authors' contributions}

YO, ZL and JM made substantial contributions to the conception and design of the study and were involved in writing and drafting the manuscript. HM and XW were responsible for performing the research and data collection, analysis and interpretation. SY and AT participated in critical revision of the manuscript. All authors read and approved the final manuscript.

\section{Ethics approval and consent to participate}

This study was approved by the Institutional Review Board (IRB) of Changsha Medical University. Informed written consent was obtained from the students who agreed to participate in this study, and their participation was voluntary. Permission was obtained from school authorities to conduct the study.

\section{Competing interests}

The authors declare that they have no competing interests.

\section{Publisher's Note}

Springer Nature remains neutral with regard to jurisdictional claims in published maps and institutional affiliations.

\section{Author details}

${ }^{1}$ School Key Discipline of Nutrition and Food Hygiene, Public Health School, Changsha Medical University, Changsha, People's Republic of China. 2Department of Dermatology and Venereology, Shenzhen Nanshan Center for Chronic Disease Control, Shenzhen, People's Republic of China. ${ }^{3}$ Shenzhen Pingshan Maternal and Child Health Hospital, Shenzhen 518122 People's Republic of China. ${ }^{4}$ Hunan Institute for Tuberculosis Control and Hunan Chest Hospital, Changsha, People's Republic of China. ${ }^{5}$ Yongzhou Center for Disease Control and Prevention, Yongzhou, People's Republic of China. ${ }^{6} H u n a n$ Province Cancer Hospital, Changsha, People's Republic of China. ${ }^{7}$ Xiangya School of Public Health, Central South University, Changsha, People's Republic of China.

Received: 23 October 2017 Accepted: 30 May 2018

Published online: 13 June 2018

\section{References}

1. World Health Organization. Available at: WHO/HTM/STB/2006.35. Last access February 2014. In: Stop TB partnership and the World Health Organization. The global plan to stop tuberculosis, 2006-2015. Geneva: WHO; 2006.

2. MC R, Uplekar MW. WHO's new stop TB strategy. Lancet. 2006;367(9514):952-5.

3. Dye $C$, Maher D, Weil D, et al. Targets for global tuberculosis control. Int J Tuberc Lung Dis. 2006;10(4):460-2.

4. World Health Organization. WHO Global tuberculosis report 2015. Available from: URL: http://www.who.int/tb/publications/2015/en/. Accessed 21 Apr 2018.

5. World Health Organization. WHO Global tuberculosis report 2017. Available from: URL: http://www.who.int/tb/publications/global_report/en/. Accessed 15 Apr 2018.

6. Wang L, Zhang H, Ruan Y, et al. Tuberculosis prevalence in China, 1990-2010; a longitudinal analysis of national survey data. Lancet. 2014;383(9934):2057-64.

7. Dye $C$, Lönnroth $K$, Jaramillo $E$, et al. Trends in tuberculosis incidence and their determinants in 134 countries. Bull World Health Organ. 2009; 87(9):683-91.
8. Woith WM, Volchenkov G, Larson JL. Russian health care workers' knowledge of tuberculosis and infection control. Int J Tuberc Lung Dis. 2010;14(11):1489-92.

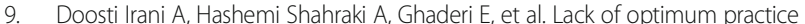
among health care workers regarding tuberculosis in Iran: a knowledge, attitude, and practice study. Am J Infect Control. 2015;43(5):e7-12.

10. Li Y, Ehiri J, Tang S, et al. Factors associated with patient, and diagnostic delays in Chinese TB patients: a systematic review and meta-analysis. BMC Med. 2013;11:156.

11. Montagna MT, Napoli C, Tafuri S, et al. Knowledge about tuberculosis among undergraduate health care students in 15 Italian universities: a crosssectional study. BMC Public Health. 2014;14:970.

12. Mehta D, Bassi $R$, Singh M, Mehta $C$. To study the knowledge about tuberculosis management and national tuberculosis program among medical students and aspiring doctors in a high tubercular endemic country. Ann Trop Med Public Health. 2012;5(3):206-8.

13. Teixeira EG, Menzies D, Cunha AJ, et al. Knowledge and practices of medical students to prevent tuberculosis transmission in Rio de Janeiro, Brazil. Rev Panam Salud Publica. 2008;24(4):265-70.

14. Behnaz F, Mohammadzade G, Mousavi-E-Roknabadi RS, et al. Assessment of knowledge, attitudes and practices regarding tuberculosis among final year students in Yazd, Central Iran. J Epidemiol Glob Health. 2014:4(2):81-5.

15. Olakunle OS, Oladimeji O, Olalekan AW, et al. Knowledge of tuberculosis management using directly observed treatment short course therapy among final year medical students in south Western Nigeria. Pan Afr Med J. 2014;18:32.

16. Zhao Y, Ehiri J, Li D, et al. A survey of TB knowledge among medical students in Southwest China: is the information reaching the target? BMJ Open. 2013;3(9):e003454

17. Bai LQ, Xiao SY, Xie HW, et al. Knowledge and practice regarding tuberculosis among final year medical students in Hunan, China. Chin J Tuberc Respir Dis. 2003;26(8):458-61.

18. Chen W, Xia YY, Li T, et al. Analysis for the Giobal and China TB epidemic situation in 2015. J Tuberc Lung Health. 2016;5(1):32-6.

19. Laurenti P, Federico B, Raponi M, et al. Knowledge, experiences, and attitudes of medical students in Rome about tuberculosis. Med Sci Monit. 2013;19:865-74.

20. Jackson M, Harrity S, Hoffman $H$, et al. A survey of health professions students for knowledge, attitudes, and confidence about tuberculosis, 2005. BMC Public Health. 2007;7(1):219.

21. Emili J, Scott F, Upshur RE, et al. Attitudes toward tuberculosis of final year medical students from Canada, India, and Uganda. Teach Learn Med. 2002; 14(3):168-74.

22. Sunita R, Bhandari RB. Knowledge, attitude and practice against tuberculosis infection control among medical students and nursing staff. J Cont Med A Dent. 2016:4(2):29-32.

23. Emili J, Norman GR, Upshur REG, et al. Knowledge and practices regarding tuberculosis: a survey of final-year medical students from Canada, India and Uganda. Med Educ. 2001;35(6):530-6.

24. Hoffman SJ, Guindon GE, Lavis JN, et al. Surveying the knowledge and practices of health professionals in China, India, Iran, and Mexico on treating tuberculosis. Am J Trop Med Hyg. 2016;94(5):959-70.

25. Center for Disease Control in China. The operational guideline for tuberculosis control program in China. Beijing: Ministry of Health; 2008. p. 101-5.

26. Ghasemzadeh I, Aghamolaei T, Hosseini-Parandar F. Evaluation of medical students of teacher-based and student-based teaching methods in infectious diseases course. J Med Life. 2015:8(Spec Iss 3):113-7. 